\title{
The Near-Death Experience: An Integration of Cultural, Spiritual, and Physical Perspectives
}

\author{
Daryl S. Paulson, Ph.D. \\ BioScience Laboratories, Inc.
}

ABSTRACT: The near-death experience (NDE) has been studied extensively from two conflicting perspectives: that the NDE is a glimpse into an after-death state and that it is the result of a dying brain. Of late a third perspective has emerged, that of NDEs being culturally determined. I propose an integrated model in which all three perspectives are viewed with equal weight.

The near death experience (NDE) has been studied extensively from a variety of perspectives (Atwater, 1988; Becker, 1993; Berman, 1996; Blackmore, 1993; Doore, 1990; Gallup \& Proctor, 1982; Greyson \& Flynn, 1984; Kastenbaum, 1984; Kastenbaum \& Kastenbaum, 1989; Kellehear, 1996; Miller, 1997; Moody, 1975; Osis \& Haraldsson, 1997; Ring, 1980, 1984; Rinpoche, 1992; Sabom, 1982; Sutherland, 1992; Zaleski, 1987). Over the years, two major divergent groups have emerged. One suggests that NDEs may be a glimpse into an after-death life state and, at the very least, provide increased personal meaning from the subjective experience. The other views NDEs as being merely the result of a dying brain. Of late, a third perspective has entered the arena, that NDEs reflect of cultural and social influences. In the first part of this paper, I will review current literature concerning the NDE and how it applies to each of these three domains.

\section{Subjective (Spiritual) Domain}

The subjective experience of the NDEr is the area of interest for this domain, as it is the focus area for those who argue that the NDE may

Daryl S. Paulson, Ph.D., is President and Chief Executive Officer of BioScience Laboratories, Inc. Reprint requests may be addressed to Dr. Paulson there at P.O. Box 190, Bozeman, MT 59711-0190. 
provide a peek into an after-life state of being. Prominent investigators who have studied in this domain include Elisabeth Kübler-Ross, Raymond Moody, Kenneth Ring, Bruce Greyson, Carl Becker, Michael Sabom, Marie-Louise von Franz, William Serdahely, Cherie Sutherland, and Melvin Morse. Many popular writers who have experienced near-death states, such as Betty Eadie (Eadie and Taylor, 1992) and Dannion Brinkley (Brinkley and Perry, 1994), also focus in this domain.

Moody (1975) constructed an ideal or complete NDE which embodied all the common elements of the NDE and the order in which they typically occur. Although his model is the one on which all subsequent near-death research was based, it is important to keep in mind that his prototypical NDE narrative is not representative of any one person's experience but a composite of many individual experiences. Ring (1980) differentiated this "core" model into five distinct experience stages which he called the "basic thanatomimetic narrative": (1) feeling peace; (2) bodily separation; (3) entering the darkness; (4) seeing the light; and (5) entering the light. Ring (1980) described this model as linear and invariant, so that the more stages experienced, the deeper the NDE was thought to be. But as other investigators reported their findings, it became clear that the NDE was neither exclusively linear nor a process of invariant stages (Becker, 1993; Berman, 1996; Kellehear, 1996; Rinpoche, 1992; Serdahely, 1995; Sutherland, 1992).

Greyson (1993) proposed a four-fold subjective typology to be used for studying NDEs, which includes (1) cognitive, (2) affective, (3) paranormal and (4) transcendental components. The cognitive category includes thoughts and thought processes during the NDE, such as the life review, a distorted concept of time, and cognitive understanding of the NDE by the experiencer. The affective category includes the NDEr's feeling states during the NDE, such as peace, joy, bliss, and feelings of unity at a cosmic level. The paranormal category includes phenomena such as perceived travel out of one's physical body during the NDE, precognitive insights or visions experienced, extrasensory perception, and hyperacute sensual awareness. The transcendental category includes perceived travel to otherworldly realms, encounters with mystical beings, assistance by spirits, and the perception of a barrier, often referred to as "the point of no return."

It is interesting to note that there are a number of similarities between NDEs and states of consciousness described in various spiritual traditions such as Tibetan Buddhism (Govinda, 1959), yoga theory (Aurobindo, 1970, 1976; Chaudhuri, 1965), esoteric Christianity (Underhill, 1955), Theosophy (Blavatsky, 1979), and neo-Theosophy (Bailey, 1936), as well as various meditative states (Goleman, 1977; 
Shapiro and Walsh, 1984) and altered states of consciousness (Tart, 1975), particularly those occurring after the ingestion of hallucinogens or after holotropic breathing (Grof, 1988). For example, individuals participating in various spiritual practices, experiencing holotropic breathing states of consciousness, and confronting Jungian archetypal images in dreams and active imagination practices often report witnessing the various gods and goddesses of mythology, as well as their own higher Self (Aurobindo, 1976; Grof, 1988; Jung, 1980; Rowan, 1993; Vaughan, 1995; von Franz, 1997; Whitmont, 1969). These figures may relate strongly to the "being of light" (Moody, 1975) and the various religious figures often reported by NDErs. Additionally, regions of consciousness described as the void or formlessness are commonly reported and discussed in the literature as associated with various spiritual traditions and the NDE (Bailey and Yates, 1996).

\section{Objective (Physical) Domain}

The objective or physical is the focus domain of most biophysiologically oriented investigators (Blackmore, 1993; Blackmore and Troscianko, 1988; Carr, 1981, 1982; Jansen, 1991, 1997; Nuland, 1994; Persinger, 1983, 1989; Rodin, 1980, 1989). Investigators focused in this domain tend to "explain" the NDE as an expression of a dying brain, and only that. Ernst Rodin (1980) argued that, as the oxygen in the brain declines to levels that do not support lucidity, anoxia occurs, resulting in hallucinations, mostly wishful, as death engulfs the individual. Daniel Carr $(1981,1982)$ and Karl Jansen (1991, 1997) wrote that the NDE is a result of endorphins or other neurochemicals produced to relieve the person of the pain and/or terror of death. Michael Persinger (1983) argued that instability and activity in the brain's right temporal lobe are responsible for the generation of NDEs, a view that Susan Blackmore also supports. Blackmore (1993) suggested that the tunnel experience with the perceived light at the end is the result of anoxia creating cortical disinhibition.

Biophysiologically oriented investigators usually define out-of-body states as autoscopic hallucinations caused by psychic trauma to the dying brain. That is, under the stress of dying, humans dissociate from their self-identity or ego and perceive themselves to be out of their bodies, when actually they are not (Kaplan and Saddock, 1995).

Moreover, there are numerous reports of phenomena similar to NDEs, resulting from increased carbon dioxide levels in the bloodstream and anesthetics such as nitrous oxide, chloroform, ether, and ketamine 
(Blackmore, 1993; Meduna, 1950; Parkin, Miller, and Vincent, 1987). Additionally, fighter pilots subjected to rapid acceleration in training have reportedly lost consciousness from lack of blood oxygen to their brains, the so-called G-LOC phenomenon, and had near death-like experiences when they clearly were not in an "actual death episode" (Whinnery, 1989, 1997).

\section{Cultural Domain}

The term "cultural" refers to an intersubjective, shared world view attributable to social groupings (Honigmann, 1963; Merton, 1957). The world view consists of a common language, values, beliefs, rules, understanding and goals shared by groups within a society, as well as by the society as a whole. Culture is society's "personality" and is an evolutionary process that emerges as humans interact (Newman, 1997). Through culture, humans establish an order of conduct dictating how to act, how to dress, what to do, and what to say in a multitude of specific social situations (Newman, 1997; Parsons, 1951). Culture imprints humans' very ability to communicate with one another (De Saussure, 1959; Hoy, 1978; Polkinghorne, 1983).

Relative to NDEs, those who focus in the cultural domain argue that their interpretation of the NDE provides the correct explanation of the phenomenon (Doore, 1990; Kellehear, 1996; Sutherland, 1992). They point out that individuals who have NDEs report phenomena that are "culturally determined." Simply stated, a Christian tends to experience and interpret the NDE in Christian terms, a Buddhist in Buddhist terms, and an African tribal member in terms of that tribe's shared beliefs (Campbell, 1959; Eliade, 1954; Grof, 1994; Kellehear, 1996; Zaleski, 1987). This phenomenon has long been known in the field of clinical psychology, for instance, where Jungians have Jungian dreams and Jungian interpretations, Freudians have Freudian dreams and Freudian interpretations, and existentialists have existential ones (Caligor and May, 1968; Progoff, 1956; Vaughan, 1995).

\section{Which Domain Is Correct?}

The salient points of this paper are that all three NDE viewpoints are correct, because each explains the NDE from different but valid perspective, and that all three domains are interrelated. One cannot 
adequately describe the NDE without taking into account all three domains since a multi-domain reality has been encountered. Interactions between multiple domains have been discussed repeatedly in recent years, for example in the realms of developmental psychology (Alexander and Langer, 1990; Commons, Richards, and Armon, 1984; Commons, Sinnott, Richards, and Armon, 1989; Kegan, 1994; Miller and Cook-Greuter, 1994; Sinnott, 1994; Sinnott and Cavanaugh, 1991; Sternberg, 1990), in statistical model building (Bailey, 1977; Box, Hunter, and Hunter, 1978; Christensen, 1977; Gibbons, 1976; Johnson and Wichern, 1982; Montgomery, 1991; Neter and Wasserman, 1974; Paulson, 1995; Rivett, 1980; Shapiro and Gross, 1981) and in qualitative experimental design processes (Borg and Gall, 1989, Denzin and Lincoln, 1994; Moustakas, 1990, 1994; Patton, 1990; Paulson, 1997b).

Early classical Greek philosophy categorized, and thus differentiated, human life into three spheres: morality, science, and art, which were constituents of Plato's "The Good, the True, and the Beautiful" (Copleston, 1960). The Good (morality) represented ethics and justice; the Beautiful (art), personal subjective aesthetics; and the True, the objective reality represented by science. Differentiation ultimately led to dissociation of the three life spheres, and to a large degree is what defines modernity (Anderson, 1995; Cahoone, 1996). Once dissociation occurred, science grew dramatically in both size and success, proclaiming that the other two spheres were inferior.

Ken Wilber $(1995,1996,1997)$, a human science theorist, has further refined and integrated these three categories. The subjective, aesthetic areas corresponding to subjective beauty and valuation in general can be described in "I" terms. Morality, or the Good, which involves intersubjective, shared, mutual understanding, can be described in "We" terms. Truth, being objective, empirical knowledge, can be described in "It" terms. Additionally, Wilber argued (1995) that science (It) commits a logical error by reducing the other two spheres, " $\mathrm{I}$ " and "We," to "Its." A number of other individuals have voiced the same concern (Assagioli, 1965; Bugental, 1965; Maslow, 1966, 1971; May, 1953; Polanyi, 1958; Polkinghorne, 1983; Schneider and May, 1995; von Bertalanffy, 1968).

According to Wilber $(1995,1996,1997)$, these domains-the "Big Three" - are represented, to some degree, in all phenomena. In the final section of this paper, I will show how the "Big Three" describe the NDE, as illustrated in Figure 1, keeping in mind that they are interdependent. 


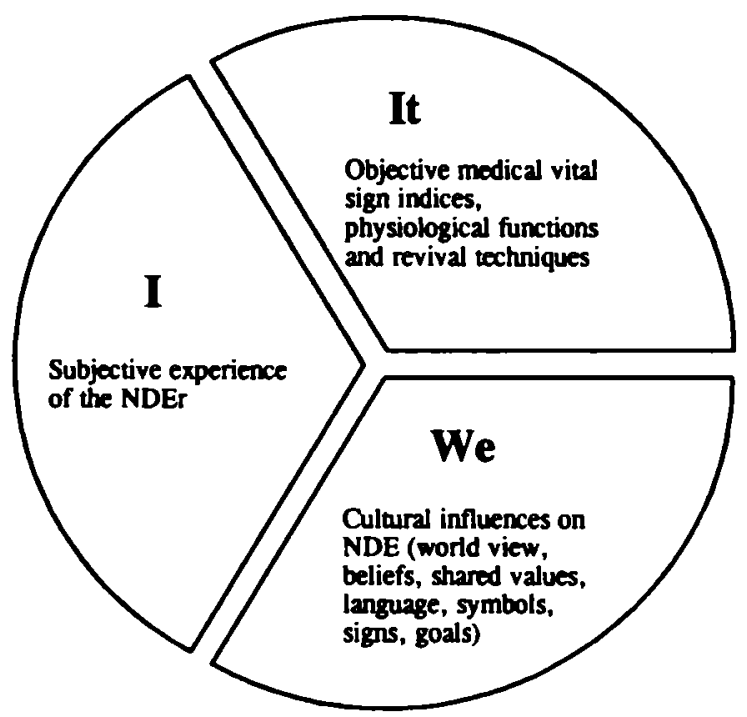

Figure 1. Near-death experience composed of Objective (It), Subjective (I), and Cultural (We) Domains.

\section{The Near Death Experience in Terms of the "Big Three"}

The objective domain, described as the "It" domain, represents medical vital signs, physiological functions of the NDEr, as well as revival procedures employed. In short, this "It" domain is the "objective (physical) domain" previously discussed. Cultural aspects, described as the "We" domain, correspond to the previously discussed "cultural domain." The personal subjective experience exists in the sphere of the " $I$ " domain. It typifies what I have called the "subjective (spiritual) domain."

\section{A General Approach to Research Designs}

There are a number of valid experimental approaches to collecting useful data, such as the heuristic, phenomenological, or biostatistical (Montgomery, 1991; Moustakas, 1990, 1994; Patton, 1990; Paulson, $1995,1997 \mathrm{~b}, 1998)$, that provide accurate and reliable information as long as the theories generated from the data are based on the collected data (Glaser and Strauss, 1967). 
The validity claims of each of the three domains can be confirmed, denied, validated, or rejected, on the basis of incisive criteria of fallibility (Audi, 1995; Regis, 1959; Wilber, 1995). There are three general criteria in conducting a valid study, which provide valid data for each of the three domains. The first criterion is use of a nonbiased, impartial research design, either qualitative or quantitative, to collect accurate and precise data (Borg and Gall, 1989; Paulson, 1995). In order to assure validity, research designs must satisfy "internal validity" requirements, such as random sampling, nonbiased sampling or questioning, nonconfounding of variables, measuring or describing significant variables using appropriate instrumentation, not confusing correlation with causation, awareness of one's own bias, prevention or acknowledgment of variable interaction, sufficient sample size to reduce the probability of both Type I and Type II errors, and prevention of the Hawthorne and John Henry effects (Borg and Gall, 1989; Campbell and Stanley, 1963; Denzin and Lincoln, 1994; Gibbons, 1976; Goldstein, 1964; Patton, 1990; Paulson, 1987; Velleman and Hoaglin, 1981).

The second criterion in conducting a valid study is that interpretation must be grounded in the collected data. That is, the interpretation must fit the data; the data must not be "massaged" to fit the interpretation or model (Ehrenberg, 1975; Moustakas, 1990, 1994; Patton, 1990; Paulson, $1987,1995)$. The third criterion is that research studies should also be replicated in other geographic locations, using different subjects, and different investigators, to confirm the results obtained and the interpretation of those results. This will assist in assuring the "external validity" of the results (Montgomery, 1991; Patton, 1990; Paulson, 1995, 1997a).

\section{Validity of Each Sphere}

The "I" domain, the subjective (spiritual) perspective, is the region of subjective experience of the NDEr during the near death episode. Valid study results require truthfulness on the part of the NDEr in reporting the experience (Merton, 1957; Moustakas, 1990; Wilber, 1995). Since one is not dealing with observable behavior, but with internal states of consciousness, the only way one can access the NDEr's interior is through dialogue and interpretation. Two invalidating situations, termed sociologically the manifest and latent problems (Merton, 1957; Moustakas, 1994; Patton, 1990), may arise in interpreting the NDE phenomenon. The manifest problem occurs when the NDEr is consciously not telling the truth about his or her subjective experience. It 
is viewed as a surface structure problem, for it is more easily identified than is the latent problem. The latent problem occurs when the NDEr is not consciously aware of being untruthful due to the action of psychological defense mechanisms, such as repression, suppression, or denial, preventing accurate NDE recall. This is considered a deep structure problem, for it is very difficult to identify. The validity claim in this area is based, then, not only on the NDEr's willingness, but on his or her ability to report truthfully the inner experience (Moustakas, 1994). And if the NDEr is telling the truth, is it the whole truth, or are deeper, unrecognized truths present (Wilber, 1995)? Whether or not the NDE is a peek into a life-after-death stage can be neither confirmed nor refuted. That the NDE can have an effect on the experiencer's post NDE life has been confirmed (Bailey and Yates, 1996; Ring, 1984; Sutherland, 1992).

The "It" domain, the objective (physical) perspective, is the region of observable physiological/biochemical characteristics of the NDEr, such as blood pressure, electrocardiogram, and carbon dioxide and oxygen blood gas levels (Gilman, Goodman, Rall, and Murad, 1985). For the data to be valid, they must accurately represent the NDEr's physical indices (Berveridge, 1957; Box, Hunter, and Hunter, 1978; Neter and Wasserman, 1974; Paulson, 1997a). There are, of course, surface and deep layers of truth, but these are available through observation, rather than interpretation. Deeper levels of observation become ever more available as new methods and more sensitive monitoring equipment come into use (Bailey, 1977).

The "We" domain, the cultural perspective, is dependent upon understanding the NDEr's cultural nuances, his or her morals, ethics, values, religious beliefs, and cultural world views, and, therefore, it is dependent on interpretation (Carr, 1948; Habermas, 1973; Searle, 1995). For the data to be valid, the researcher must command a knowledge, at once both broad and detailed, of the culture in question.

It should also be recognized that much of what we call reality is constructed or invented by cultures (Newman, 1997). The degree to which reality is constructed, however, is bound by objective reality (Searle, 1995). What humans believe to be true or real is often only partially so. Sociologists (Geertz, 1973; Merton, 1957; Newman, 1997; Parsons, 1951) are in general agreement, stating that three stages are present in socially-constructed reality: externalization, objectivation, internalization. Externalization is the initial stage, in which a theory, opinion or belief is accepted as "tentatively" being true. Objectivation is the next stage, in which the theory, opinion or belief is accepted as "fact." Internalization is when the "accepted fact" is incorporated into a person's psyche as "absolute" truth. 
In evaluating and interpreting the NDE from the cultural perspective, at least two levels of meaning exist: surface and deep. The surface level looks at cultural motifs, the shared symbology of the culture (Merton, 1957). Yet at a deeper level, the cultural aspect of the NDE reinforces the cultural group's identity, leading to a deeper bonding of those in the culture (Newman, 1997; Parsons, 1951). For both the surface and deep structures, it is important to determine if the interpretation is really true. If true, is it the whole truth or are there other truths at deeper levels?

\section{Integration}

Because each of the three viewpoints partially describes the NDE, it will be most valuable to integrate all three into one cohesive model. Robert Kegan (1994), Jan Sinnott (1994), and Wilber (1995, 1996, 1997) have argued that it may be useful to apply "post-formal" cognitive processes when trying to understand complex, multi-dimensional phenomena such as the NDE, holding and integrating various divergent domains within one model. Each of the three domain perspectives, then, must be held in mind simultaneously. That is, each domain must be valued for its valid, but partial contribution to understanding this multidimensional phenomenon. For example, it is to be expected that physical correlates exist that correspond to the subjectively experienced phenomena of NDEs. Hence, both are equally important to understanding NDEs. Additionally, one's subjective experiences and interpretations of them by an investigator will be colored by the shared cultural beliefs, values, and expectations of both (Carr, 1948; Merton, 1957; Parsons, 1951). Integration, then, does not favor any perspective; it is aperspective (Paulson, 1993). With this said, investigators can still study their preferred domain of interest; however, they should recognize that greater understanding of the NDE requires the acknowledgment of truths revealed in all three domains.

\section{Conclusion}

In conclusion, the NDE can be studied from a subjective perspective, a physical perspective, and a cultural perspective. Each perspective has a portion of the truth, but is not the whole truth. To better understand the NDE is to study it from a full model, three-sphere perspective, honoring the insight to this unique phenomenon provided by each domain. 


\section{References}

Alexander, C. N., and Langer, E. J. (1990). Higher stages of human development: Perspectives on adult growth. New York, NY: Oxford University Press.

Anderson, W. T. (1995). The truth about the truth: De-confusing and reconstructing the postmodern world. New York, NY: Tarcher/Putnam.

Assagioli, R. (1965). Psychosynthesis. New York, NY: Hobbs, Dorman.

Atwater, P. M. H. (1988). Coming back to life: The after-effects of the near-death experience. New York, NY: Dodd, Mead.

Audi, R. (1995). The Cambridge dictionary of philosophy. New York, NY: Cambridge University Press.

Aurobindo, S. (1970). The life divine. Pondicherry, India: Aurobindo Trust.

Aurobindo, S. (1976). The synthesis of yoga. Pondicherry, India: Aurobindo Trust.

Bailey, A. A. (1936). Esoteric psychology. New York, NY: Lucis.

Bailey, L. W., and Yates, J. L. (1996). The near death experience: A reader. New York, NY: Routledge.

Bailey, T. J. (1977). Mathematics, statistic, and systems for health. New York, NY: John Wiley.

Becker, C. B. (1993). Paranormal experience and the survival of death. Albany, NY: State University of New York Press.

Berman, P. L. (1996). The journey home. New York, NY: Pocket Books.

Berveridge, W. I. B. (1957). The art of scientific investigation (rev. ed.). New York, NY: Norton.

Blackmore, S. J. (1993). Dying to live: Near-death experiences. Buffalo, NY: Prometheus.

Blackmore, S. J., and Troscianko, T. (1988). The physiology of the tunnel. Journal of Near-Death Studies, 8, 15-28.

Blavatsky, H. P. (1979). The secret doctrine (7th ed.). Adyar, India: Theosophical Publishing House.

Borg, W. R., and Gall, M.D. (1989). Educational research (5th ed.). White Plains, NY: Longman.

Box, G .E. P., Hunter, W. G., and Hunter, J. S. (1978). Statistics for experimenters: An introduction to design, data analysis, and model building. New York, NY: Wiley.

Brinkley, D., and Perry, P. (1994). Saved by the light. New York, NY: Villard Books.

Bugental, J. F. T. (1965). The search for authenticity: An existential-analytic approach to psychotherapy. New York, NY: Holt, Rhinehart, and Winston.

Cahoone, L. E. (Ed.). (1996). Modernism to postmodernism: An anthology. Cambridge, MA: Blackwell.

Caligor, L., and May, R. (1968). Dreams and symbols. New York, NY: Basic Books.

Campbell, D. T., and Stanley, J. C. (1963). Experimental and quasi-experimental designs for research. Boston, MA: Houghton Mifflin.

Campbell, J. (1959). The masks of god: Primitive mythology. New York, NY: Viking.

Carr, D. (1981). Endorphins at the approach of death. Lancet, 826, 390-98.

Carr, D. (1982). Pathophysiology of stress-induced limbic lobe dysfunction: A hypothesis for NDEs. Anabiosis: The Journal of Near-Death Studies, 2, 75-89.

Carr, L. J. (1948). Situational analysis. New York, NY: Harper and Brothers.

Chaudhuri, H. (1965). Integral yoga. San Francisco, CA: Institute of Asian Studies.

Christensen, L. B. (1977). Experimental methodology. Boston, MA: Allyn and Bacon.

Commons, M. L., Richards, F. A., and Armon, C. (1984). Beyond formal operations. New York, NY: Praeger.

Commons, M. L., Sinnott, J. D., Richards, F. A., and Armon, C. (1989). Adult development, Vol. 1. Westport, CT: Praeger.

Copleston, F. (1960). A history of philosophy, Vol. 1. New York: Image.

Denzin, N. K., and Lincoln, Y. S. (1994). Handbook of qualitative research. Thousand Oaks, CA: Sage. 
De Saussure, F. (1959). Course in general linguistics. New York, NY: Philosophical Library. Doore, G. (Ed.). (1990). What survives? Los Angeles, CA: Tarcher.

Eadie, B., and Taylor, C. (1992). Embraced by the light. Placerville, CA: Gold Leaf Press.

Ehrenberg, A. S. C. (1975). Data reduction: Analyzing and interpreting statistical tests (rev. ed.). New York, NY: Wiley.

Eliade, M. (1954). The myth of the eternal return: On cosmos and history (W. R. Trask, trans.). Princeton, NJ: Princeton University Press.

Gallup, G., and Proctor, W. (1982). Adventures in immortality: A look beyond the threshold of death. New York: McGraw-Hill.

Geertz, C. (1973). Interpretation of cultures. New York, NY: Basic Books.

Gibbons, J. D. (1976). Nonparametric methods for quantitative analysis. New York, NY: Holt, Rinehart and Winston.

Gilman, A. G., Goodman, L. S., Rall, T. W., and Murad, F. (1985). The pharmacological basis of therapeutics. (7th ed.). New York, NY: MacMillan.

Glaser, B. G., and Strauss, A. L. (1967). Discovery of grounded theory: Strategies for qualitative research. Chicago, IL: Aldine de Gruyter.

Goldstein, A. (1964). Biostatistics. New York, NY: MacMillan.

Goleman, D. (1977). The meditative mind. New York, NY: Tarcher/Putnam.

Govinda, A. (1959). Foundations of Tibetan mysticism. New York, NY: Rider.

Greyson, B. (1993). Varieties of near-death experience. Psychiatry, 56, 390-99.

Greyson, B., and Flynn, C. P. (1984). The near-death experience: Problems, prospects, perspectives. Springfield, IL: Charles C Thomas.

Grof, S. (1988). The adventure of self discovery: Dimensions of consciousness and new perspectives in psychotherapy and inner exploration. Albany, NY: State University of New York Press.

Grof, S. (1994). Books of the dead. New York: Thames and Hudson.

Habermas, J. (1973). Theory and practice (J. Viertel, trans.). Boston: Beacon Press.

Honigmann, J. J. (1963). Understanding culture. New York: Harper and Row.

Hoy, D. (1978). The critical circle: Literature, history and philosophical hermeneutics. Berkeley, CA: University of California Press.

Jansen, K. L. R. (1991). Transcendental explanations and the near-death experience. Lancet, 337, 244.

Jansen, K. L. R. (1997). The ketamine model of the near-death experience: A central role for the N-methyl-D-aspartate receptor. Journal of Near-Death Studies, 16, 5-26.

Johnson, R. A., and Wichern, D. W. (1982). Applied multivariate statistical analysis. Englewood Cliffs, NJ: Prentice-Hall.

Jung, C. G. (1980). Collected works. Vol. 18: The symbolic life (corrected ed.) (G. Adler and R. F. Hull, eds.). Princeton, NJ: Princeton University Press/Bollinger.

Kaplan, H. I., and Saddock, B. J. (1995). Comprehensive textbook of psychiatry (6 ${ }^{\text {th }}$ ed.). Philadelphia, PA: Williams and Wilkins.

Kastenbaum, R. (1984). Is there life after death? Agincourt, Ontario: Methuen.

Kastenbaum, R., and Kastenbaum B. (1989). Encyclopedia of death. Phoenix, AZ: Oryx Press.

Kegan, R. (1994) In over our heads: The mental demands of modern life. Cambridge, MA: Harvard University Press.

Kellehear, A. (1996). Experiences near death: Beyond medicine and religion. New York, NY: Oxford University Press.

Maslow, A. H. (1966). The psychology of science. New York, NY: Harper and Row.

Maslow, A. H. (1971). The farther reaches of human nature. New York, NY: Viking.

May, R. (1953). Man's search for himself. New York, NY: Norton.

Meduna, L. J. (1950). The effect of carbon dioxide upon functions of the brain. In Carbon dioxide therapy: A neurophysiological treatment of nervous disorders. Springfield, IL: Charles C Thomas.

Merton, R. K. (1957). Social theory and social structure. Glencoe, IL: Free Press. 
Miller, M. E., and Cook-Greuter, S. R. (1994). Transcendence and mature thought in adulthood: The further reaches of adult development. Lanham, MD: Rowman and Littlefield. Miller, S. (1997). After death. New York, NY: Simon and Schuster.

Montgomery, D. C. (1991). Design and analysis of experiments (3rd ed.). New York, NY: Wiley.

Moody, R. A. (1975). Life after life. St. Simons Island, GA: Mockingbird Books.

Moustakas, C. (1990). Heuristic research: Design, methodology, and applications. Thousand Oaks, CA: Sage.

Moustakas, C. (1994). Phenomenological research methods. Thousand Oaks, CA: Sage.

Neter, J. and Wasserman, W. (1974). Applied linear statistical models. Homewood, IL: Irwin.

Newman, D. M. (Ed.). (1997). Sociology: Exploring the architecture of everyday life: Readings ( $2^{\text {nd }}$ ed.). Thousand Oaks, CA: Pine Forge Press.

Nuland, S. B. (1994). How we die. New York, NY: Knopf.

Osis, K. and Haraldsson, E. (1997). What they saw ... at the hour of death: A new look at evidence for life after death. New York, NY: Avon.

Parkin, A. J., Miller, J. and Vincent, R. (1987). Multiple neuropsychological deficits due to anoxic encephalopathy: A case study. Cortex, 23,655-65.

Parsons, T. (1951). The social system. Glencoe, IL: Free Press.

Patton, M. Q. (1990). Qualitative evaluation and research methods ( $2^{\text {nd }}$ ed.). Thousand Oaks, CA: Sage.

Paulson, D. S. (1987, September). Statistical evaluations. Soap/Cosmetics/Chemical Specialties, pp. 58-67.

Paulson, D. S. (1993, Winter). Authentic integral living. Voices, pp. 58-65.

Paulson, D. S. (1995, November). Research designs. Soap/Cosmetics/Chemical Specialties, pp. 153-157.

Paulson, D. S. (1997a, May). Foodborne disease and controlling the problem. Environmental Health, pp. 15-19.

Paulson, D. S. (1997b, December). Developing effective topical antimicrobials. Soap/ Cosmetics/Chemical Specialities, pp. 58-58.

Paulson, D. S. (1998). Handbook of antimicrobial evaluations. New York, NY: Marcel Dekker.

Persinger, M. A. (1983). Religious and mystical as artifacts of temporal lobe function. Perceptual and Motor Skills, 57, 1255-62.

Persinger, M.A. (1989). Modern neuroscience and near-death experiences: Expectancies and implications. Comments on "A neurobiological model for near-death experiences." Journal of Near-Death Studies, 7, 233-239.

Polanyi, M. (1958). Personal knowledge: Towards a post-critical philosophy. Chicago, IL: University of Chicago Press.

Polkinghorne, D. (1983). Methodology for the human sciences: Systems of inquiry. Albany, NY: State University of New York Press.

Progoff, I. (1956). The death and rebirth of psychology: An integrative evaluation of Freud, Adler, Jung and Rank and the impact of their insights on modern man. New York, NY: Julian Press.

Regis, L.-M. (1959). Epistemology. New York, NY: Macmillan.

Ring, K. (1980). Life at death: A scientific investigation of the near-death experience. New York, NY: Coward, McCann and Geohegan.

Ring, $K$. (1984). Heading toward omega: In search of the meaning of the near-death experience. New York, NY: William Morrow.

Rinpoche, S. (1992). The Tibetan book of living and dying. New York, NY: HarperCollins.

Rivett, P. (1980). Model building for decision analysis. New York, NY: Wiley.

Rodin, E. A. (1980). The reality of death experiences: A personal perspective. Journal of Nervous and Mental Disease, 168, 259-263.

Rodin, E. A. (1989). Comments on "A neurobiological model for near-death experiences." Journal of Near-Death Studies, 7, 255-259. 
Rowan, J. (1993). The transpersonal: Psychotherapy and counseling. London, England: Routledge.

Sabom, M. B. (1982). Recollections of death: A medical investigation. New York, NY: Harper and Row.

Schneider, K. J., and May, R. (1995). The psychology of existence: An integrative, clinical perspective. New York, NY: McGraw-Hill.

Searle, J. R. (1995). The construction of social reality. New York, NY: Free Press.

Serdahely, W. J. (1995). Variations from the prototypic near-death experience: The individually tailored hypothesis. Journal of Near-Death Studies, 13, 185-96.

Shapiro, D. H., and Walsh, R. N. (1984). Meditation: Classic and contemporary perspectives. New York, NY: Aldine de Gruyter.

Shapiro, S. S., and Gross, A. J. (1981). Statistical model building techniques. New York, NY: Marcel Dekker.

Sinnott, J. D. (1994). Interdisciplinary handbook of adult lifespan learning. Westport, CT: Greenwood Press.

Sinnott, J. D., and Cavanaugh, J. C. (1991). Bridging paradigms: Positive development in adulthood and cognitive aging. New York, NY: Praeger.

Sternberg, R. J. (1990). Wisdom: Its nature, origins and development. New York, NY: Cambridge University Press.

Sutherland, C. (1992). Transformed by the light: Life after near-death experiences. Sydney, Australia: Bantam.

Tart, C. T. (1975). States of consciousness. New York, NY: Dutton.

Underhill, E. (1955). Mysticism: The nature and development of spiritual consciousness. New York, NY: Meridian.

Vaughan, F. (1995). The inward arc: Healing in psychotherapy and spirituality (2nd ed.). Grass Valley, CA: Blue Dolphin.

Velleman, P. F., and Hoaglin, D. C. (1981). Applications, basics and computing of exploratory data analysis. Boston, MA: Duxbury.

von Bertalanffy, L. (1968). General systems theory: Essays on its foundation and development. New York, NY: George Braziller.

von Franz, M. L. (1997). Archetypal dimensions of the psyche. Boston, MA: Shambhala.

Whinnery, J. E. (1989). Observations on the neurophysiologic theory of acceleration $(+\mathrm{Gz})$ induced loss of consciousness. Aviation Space and Environmental Medicine, 60, 589-93.

Whinnery, J. E. (1997). Psychophysiologic correlates of unconsciousness and near-death experiences. Journal of Near-Death Studies, 15, 231-58.

Whitmont, E. C. (1969). The symbolic quest: Basic concepts of analytical psychology. New York, NY: Putnam.

Wilber, K. (1995). Sex, ecology, spirituality: The spirit of evolution. Boston, MA: Shambhala.

Wilber, K. (1996). A brief history of everything. Boston, MA: Shambhala.

Wilber, K. (1997). The eye of spirit: An integral vision for a whole gone slightly mad. Boston, MA: Shambhala.

Zaleski, C. (1987). Otherworld journeys: Accounts of near-death experience in medieval and modern times. New York, NY: Oxford University Press. 